\title{
An Analysis of Medication Adherence and Patient Preference in Long-term Stable Maintenance Hemodialysis Patients in Japan
}

\author{
Masaki Ohya, Yuko Iwashita, Satoko Kunimoto, Shuto Yamamoto, Toru Mima, \\ Shigeo Negi and Takashi Shigematsu
}

\begin{abstract}
:
Objective This follow-up survey report describes medication adherence and patient preferences, beliefs, and expectations of maintenance hemodialysis treatment in Japan.

Methods This patient-reported questionnaire-based survey was conducted in six regions in Japan from September 2016 to November 2016.

Patients The questionnaire was provided to 700 patients (50-79 years old) on maintenance hemodialysis for $>3$ years who were members of the Japan Association of Kidney Disease Patients. Patients were randomly selected by a stratified sampling method based on patient distribution observed from the Japanese Society for Dialysis Therapy Renal Data Registry.

Results A total of 524 (74.9\%) complete patient questionnaires were evaluated; the mean (SD) age was 66.6 (7.2) years (men, 63.4\%) with a dialysis vintage of 16.9 (9.1) years. Adherence was high for all types of medications: between $76.7 \%$ for phosphate binders and $95.7 \%$ for antidiabetic medications. The most common reason for a missed dose was forgetting to take medication [52.5\% (117/223)]. Patient preference for oral medication was as low as $0.9 \%(1 / 110), 9 \%(31 / 345)$, and $2.9 \%(2 / 69)$ for patients who felt mental burden, felt no mental burden, and neither, respectively, with their current treatment regimen. In addition, 37.8\% (198/524) of patients responded that the elimination of 1 medication (1 tablet) would reduce their mental burden.

Conclusion The results of this survey show that overall medication adherence is high in Japanese patients on maintenance hemodialysis. While many patients perceive an absence of mental burden, they still prefer to avoid oral medication when possible.
\end{abstract}

Key words: adherence, Japan, maintenance hemodialysis, patient preference, questionnaire survey

(Intern Med 58: 2595-2603, 2019)

(DOI: 10.2169/internalmedicine.2676-19)

\section{Introduction}

For patients on long-term maintenance dialysis, the total burden of oral medication is high $(1,2)$, and poor adherence to complex multimodal therapies contributes to increased morbidity and mortality in this patient population (3). Compared to a nondialysis population, a multitude of specialized medications are needed for dialysis patients, primarily to control associated comorbidities and metabolic abnormali- ties (1), including chronic kidney disease (CKD)-mineral and bone disorder (CKD-MBD) (4). Medication adherence is therefore a crucial issue in this patient population. A systematic literature review of 19 studies revealed that nonadherence to oral medication remains an underestimated and serious problem in hemodialysis patients, with phosphate binders as the most prevalent surveyed oral medication (3). Nonadherence to medications is not only an important issue for patients but also a significant concern for clinicians, policy makers, and healthcare payers (5). 
Prior studies that specifically evaluated patient beliefs, concerns, and preferences regarding phosphate binders have shown that an increased number of oral pills does not correlate with improvements in hyperphosphatemia and may, in fact, reduce the health-related quality of life (6-8). Furthermore, as the dialysis vintage (length of time on dialysis) can be as high as 35 years in Japan (longest dialysis vintage reported to be 46 years and 6 months) (9), it is likely that, depending on the care given, the care provider, and the quality of care provided, aging and a decreased cognitive function might play a role in medication adherence (10). Studies have shown that medication adherence rates are higher in hemodialysis patients with hyperphosphatemia who are $\geq 60$ years of age than in their younger counterparts $(11,12)$. In addition, it is anticipated that an increasing rate of medication nonadherence will contribute to the growing problem of leftover medication $(13,14)$. According to a study from the Japan Pharmaceutical Association, leftover medication is a significant concern in Japan, with an annual cost of 47.5 billion yen $(15,16)$.

We previously reported the results of a survey pertaining to drug burden as an original article. The previous study showed that the number, type, and frequency of oral medications taken by hemodialysis patients were high and did not differ markedly between dialysis and nondialysis days (2). The pill burden was higher than in a previous report from the Japanese Ministry of Health, Labour and Welfare (17). However, extensive data on medication adherence and patient preference were collected in our previous survey, and it was not feasible to present these data in the initial report (2). In Japan, the availability of data regarding drug burden and treatment adherence in patients on maintenance dialysis is limited $(1,2)$, with no existing data on patient preferences, beliefs, or expectations concerning this subject. Therefore, a questionnaire-based survey was conducted in Japan to evaluate these aspects in patients on maintenance dialysis.

We herein report the remaining survey results pertaining to medication adherence and patient preferences, beliefs, and expectations concerning maintenance hemodialysis treatment.

\section{Materials and Methods}

\section{Survey objective}

The objective of this survey was to explore the factors involved in oral medication compliance, reporting of leftover medications, and perception of drug burden in hemodialysis patients.

\section{Survey design and patients}

A questionnaire-based survey was conducted from September 2016 to November 2016 in six regions in Japan: Hokkaido/Tohoku, Kanto, Chubu, Kinki, Chugoku/Shikoku, and Kyushu. A detailed description of the study methods has been published previously (2).

In brief, the survey was conducted in patients who were between 50 and 79 years of age, had been on maintenance hemodialysis for $>3$ years, and were enrolled members of the Japan Association of Kidney Disease Patients (JAKDP). Patients on peritoneal dialysis or concomitant peritoneal dialysis and hemodialysis were excluded.

The survey was approved by the ethics review board of Wakayama Medical University. Informed consent was obtained from all patients included in the study.

\section{Survey questionnaire}

Self-administered survey forms were provided to the eligible patients. The questionnaire was anonymous and comprised 22 questions. In this follow-up report, we limit our presentation to survey results that pertained to medication compliance and patient preferences, beliefs, and expectations regarding treatment.

\section{Assessments and statistical analyses}

Using multiple choice questions, we assessed medication compliance, reasons for missed medications, compliance instructions, reporting of leftover medications, and reasons for not reporting leftover medications. Medication compliance and reasons for missed medications were also analyzed by medication type. We also investigated whether or not patients believed that eliminating one medication from their regimen would help relieve drug burden, and whether or not they preferred injections during dialysis over oral medications. Descriptive statistics were used to evaluate the survey data.

\section{Results}

\section{Demographic and baseline characteristics}

Of the 700 eligible patients who received the questionnaire, $535(76.4 \%)$ participated in the survey. Of these, the completed questionnaires of 524 patients $(74.9 \%)$ were considered valid for the evaluation.

The mean [standard deviation (SD)] age of the respondents was 66.6 (7.2) years (men, 63.4\%) with a mean dialysis vintage of 16.9 (9.1) years (Table 1). The age distribution was relatively even, with $19.3 \%$ of patients in their 50 s, $40.7 \%$ in their $60 \mathrm{~s}$, and $38.2 \%$ in their 70 s. In terms of dialysis vintage, $23.7 \%$ of patients had received dialysis for 39 years, $37.0 \%$ for $10-19$ years, $23.3 \%$ for $20-29$ years, and $10.5 \%$ for $\geq 30$ years. Overall, the age, gender, and regional distribution of the respondents were similar to those of the national dialysis patient population reported in December 31, 2014, in the Japanese Society for Dialysis Therapy Renal Data Registry, with the exception of a longer average dialysis vintage in the survey population.

\section{Compliance and leftover medications}

Adherence to medications was high $[93.2 \% \quad(1,170 /$ 
$1,255)]$, and a majority of the patients responded that they take medicines as instructed [84.5\% $(1,060 / 1,255)]$ or miss no more than 1 dose of medication per week $[8.8 \%$ (110/ 1,255)] (Fig. 1A). In the case of nonadherence, patients reported that they discuss their leftover medicines mostly with a nurse [45.7\% (145/317)], doctor [23.0\% (73/317)], pharmacist $[4.1 \%(13 / 317)]$, clinical engineer $[0.3 \%(1 / 317)]$, or no one [24.9\% (79/317)] (Fig. 1B).

The most common reason for a missed dose was forget-

Table 1. Patient Characteristics.

\begin{tabular}{lc}
\hline & $\begin{array}{c}\text { Completed Questionnaires } \\
(\mathrm{n}=524)\end{array}$ \\
\hline Male/female, $\mathrm{n}(\%)$ & $332 / 182(63.4 / 34.7)$ \\
Age, years, mean (SD) & $66.6(7.2)$ \\
Dialysis vintage, years, mean (SD) & $16.9(9.1)$ \\
Comorbidity, $\mathrm{n}(\%)$ & \\
Hypertension & $214(40.8)$ \\
Cardiovascular disease & $138(26.3)$ \\
Diabetes & $82(15.6)$ \\
Dyslipidemia & $15(2.9)$ \\
Gastrointestinal disease & $65(12.4)$ \\
Respiratory disease & $29(5.5)$ \\
Cerebrovascular disease & $32(6.1)$ \\
Cancer & $17(3.2)$ \\
Other & $76(14.5)$ \\
Unknown & $32(6.1)$ \\
Concomitant drugs, $\mathrm{n}(\%)$ & \\
Phosphate binders & $53(10.1)$ \\
Antihypertensives & \\
Calcimimetics & $305(92.2)$ \\
Vitamin D products & $266(50.8)$ \\
Antidiabetic medications & $196(37.4)$ \\
\hline
\end{tabular}

ting to take medication, reported by approximately half the patients who claimed nonadherence [52.5\% (117/223)]. Other reasons for nonadherence are mentioned in Table 2.

Explanations concerning medication adherence were provided for $57.9 \%(751 / 1,297)$ of the prescriptions for the 5 drug classes (CKD-MBD-related drugs: vitamin D products, phosphate binders, calcimimetics, antihypertensives, and antidiabetic medications). The purpose of almost all prescription medicines given to patients $[94.7 \%(1,229 / 1,298)]$ was explained by a doctor or pharmacist. Among them, $90.5 \%$ $(1,175 / 1,298)$ of the explanations for drug prescriptions were understood well, while $4.2 \%(54 / 1,298)$ were not understood well. An explanation for the purpose of the medication was not provided for $2.1 \%(27 / 1,298)$ of the prescriptions (Fig. 2).

The mean (SD) number of tablets the patients received at their most recent medication refill visit was 103.6 (130.5). The mean (SD) percentage of leftover tablets at the next medication refill visit (or next clinic visit) was $7.8 \%$ $(16.6 \%)$. The percentage of leftover phosphate binders was the highest of any medication type [8.6\% (18.1\%)], followed by antihypertensives [7.5\% (18.7\%)], calcimimetics [4.8\% $(15.9 \%)]$, vitamin D products $[3.8 \%(12.3 \%)]$, and antidiabetic medications $[3.0 \%(8.1 \%)]$ (Fig. 3).

The reasons given by $15.3 \%(80 / 524)$ of the patients (including multiple responses to the question) who responded that they do not report to anybody about leftover medication were "they will find out that I am not compliant and it is hard to talk about it" [20.3\% (16/79) patients with responses], "I am comfortable with leftover medications" [24.1\% (19/79)], "it is a hassle to voluntarily talk about the leftover medications" [8.9\% (7/79)], and "I do not want to be managed more strictly in the future" $[5.1 \%(4 / 79)]$. The

\section{A. Question: Do you sometimes miss a dose of oral medication that you were instructed to take regularly?}

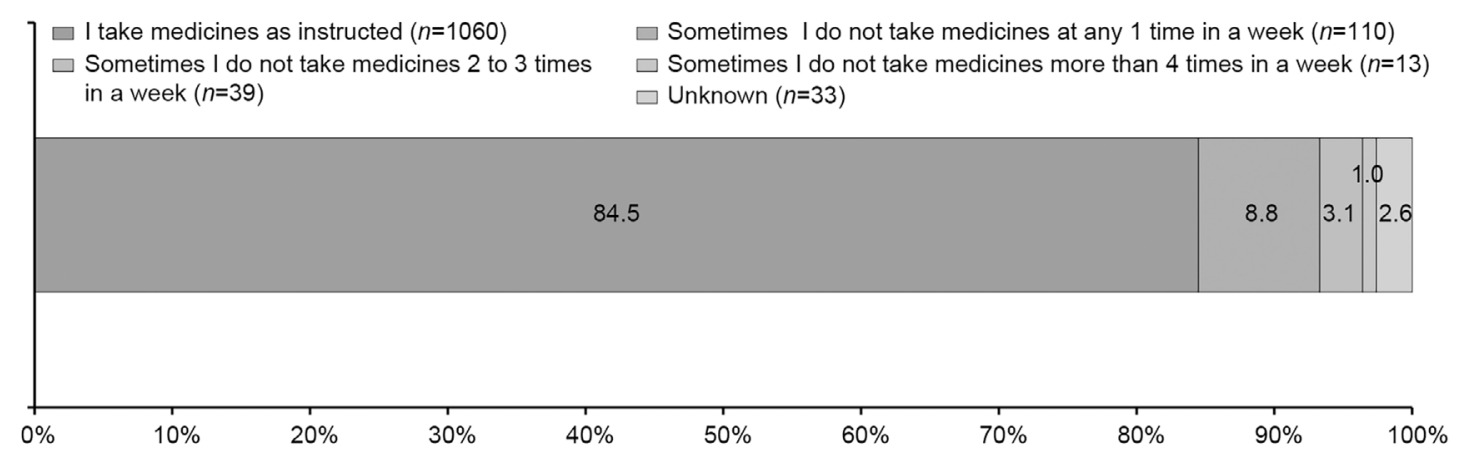

B. Question: To whom do you report your leftover medications most often?

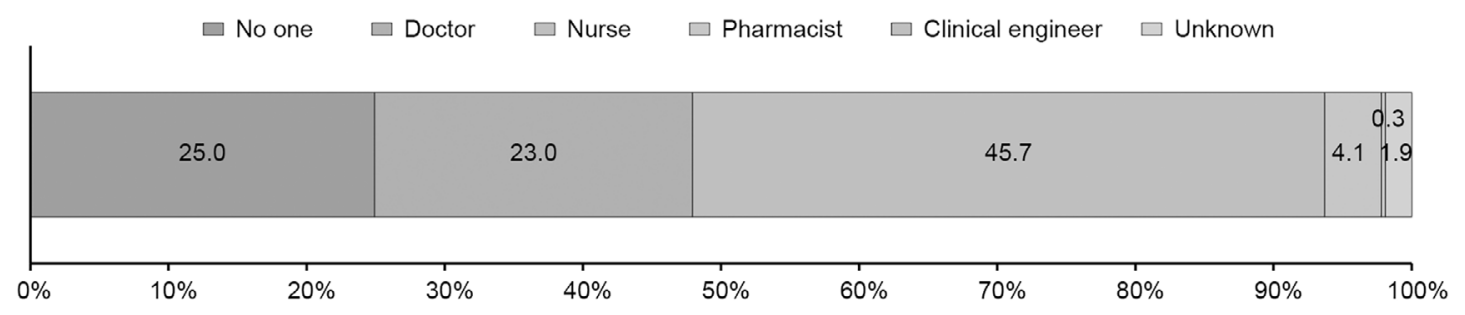

Figure 1. (A) Medication compliance status and (B) reporting of nonadherence. 
Table 2. Reasons for Missed Medication.

\begin{tabular}{lc}
\hline \multicolumn{1}{c}{ Question: Why do you sometimes miss taking your medications? } & $\begin{array}{c}\text { Respondents } \\
\mathrm{n}=223 \\
\mathrm{n}(\%)\end{array}$ \\
\hline Because types and frequency of medicines to take are too many and difficult to follow & $6(2.7)$ \\
Because I sometimes accidentally forget to take medicines & $117(52.5)$ \\
Because taking medicines does not make significant differences & $7(3.1)$ \\
Because I sometimes find symptoms like side effects after taking these medicines & $7(3.1)$ \\
I am instructed to adjust dose by myself according to my condition by doctor & $25(11.2)$ \\
Because I decide by myself if I should take medicines or not & $23(10.3)$ \\
Unknown & $38(17)$ \\
\hline
\end{tabular}

Question: Did you receive an explanation of the purpose of your medications from a doctor or pharmacist?
A. Explanation for medication adherence provided by doctor or pharmacist
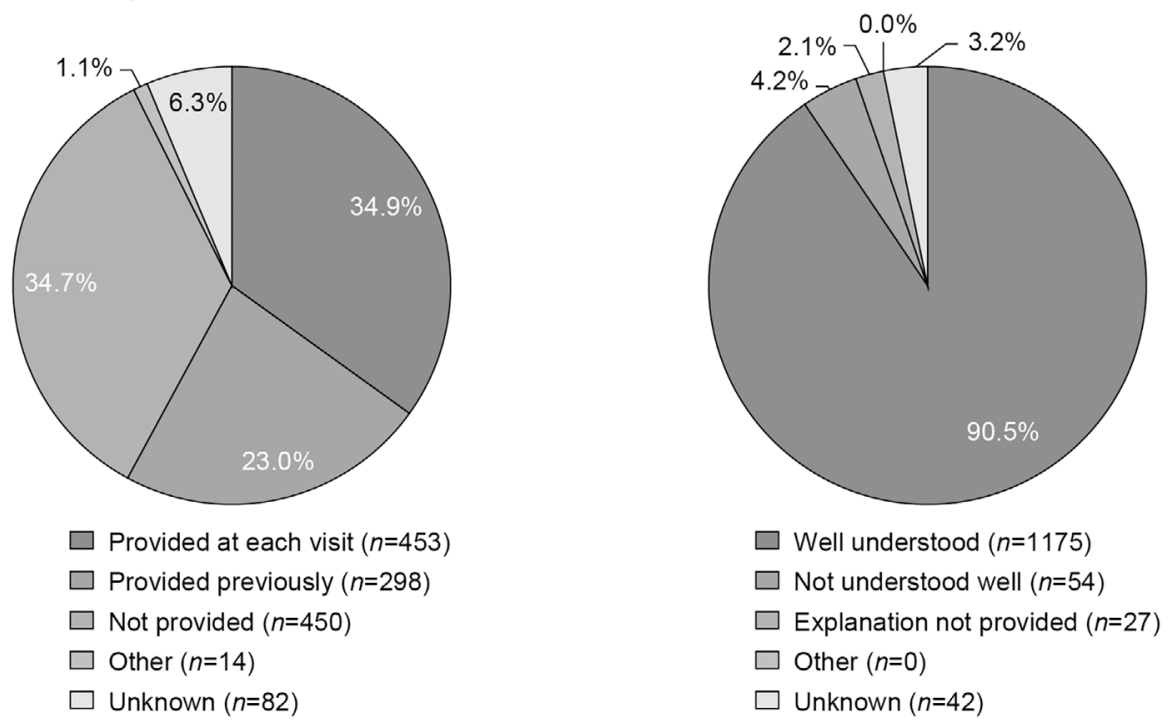

B. Patient understanding of explanation for adherence

Figure 2. (A) Instructions for medication adherence for all drug classes and (B) patient understanding of instructions for all drug classes.

Question: How many tablets of medication do you receive at any one visit to the clinic? How many tablets are left when you visit the clinic next time?

\begin{tabular}{|c|c|c|c|c|}
\hline & & $\begin{array}{l}\text { Number of tablets } \\
\text { you receive at one } \\
\text { time at the clinic }\end{array}$ & $\begin{array}{l}\text { How many tablets are } \\
\text { left when you visit the clinic } \\
\text { next time? }\end{array}$ & Unknown \\
\hline A & $\begin{array}{l}\text { Vitamin D } \\
\text { products }\end{array}$ & Usually tablets & $\begin{array}{l}\text { tablets among what I } \\
\text { received at the previous visit } \\
\text { will be left over } \\
\square \text { None left over (I take all) }\end{array}$ & $\square$ \\
\hline B & $\begin{array}{l}\text { Medicines } \\
\text { to decrease } \\
\text { phosphorus } \\
\text { level }\end{array}$ & Usually tablets & $\begin{array}{l}\text { tablets among what I } \\
\text { received at the previous visit } \\
\text { will be left over } \\
\square \text { None left over (I take all) }\end{array}$ & ㅁ \\
\hline C & $\begin{array}{l}\text { Medicines } \\
\text { to decrease } \\
\text { parathyroid } \\
\text { hormone }\end{array}$ & Usually & $\begin{array}{l}\text { tablets among what I } \\
\text { received at the previous visit } \\
\text { will be left over } \\
\square \text { None left over (I take all) }\end{array}$ & 口 \\
\hline D & $\begin{array}{l}\text { Hypertension } \\
\text { medicines }\end{array}$ & Usually & $\begin{array}{l}\text { tablets among what I } \\
\text { received at the previous visit } \\
\text { will be left over } \\
\square \text { None left over (I take all) }\end{array}$ & $\square$ \\
\hline E & $\begin{array}{l}\text { Diabetes } \\
\text { medicines }\end{array}$ & Usually tablets & $\begin{array}{l}\text { tablets among what I } \\
\text { received at the previous visit } \\
\text { will be left over } \\
\square \text { None left over (I take all) }\end{array}$ & ㅁ \\
\hline
\end{tabular}

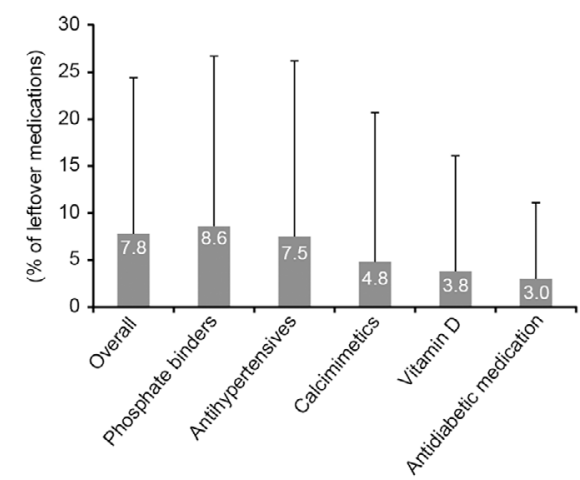

Figure 3. Percentage [mean (SD)] of leftover medications. 


\section{A. Medication adherence}

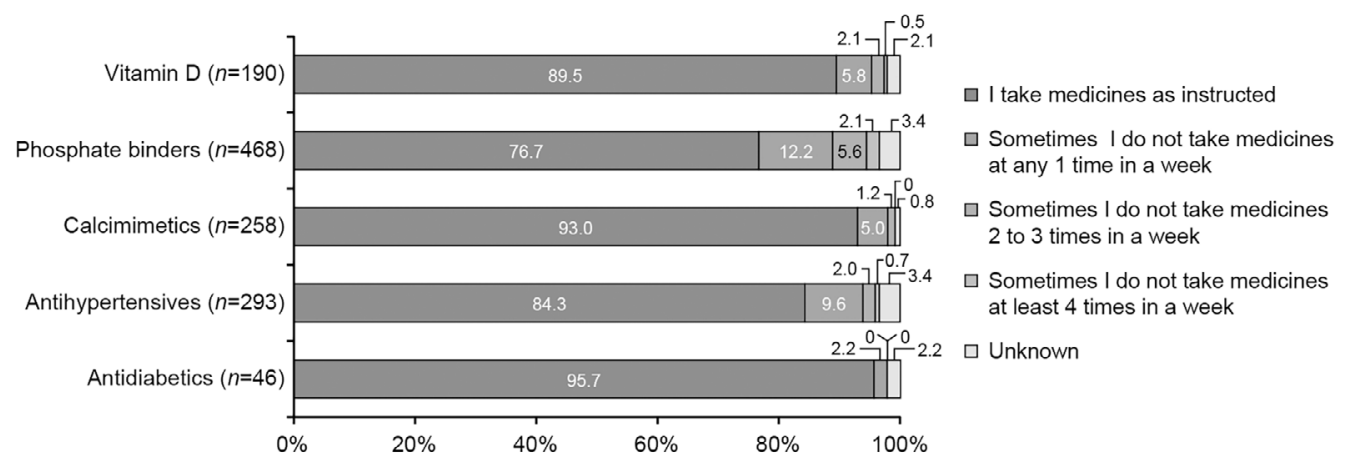

B. Reasons for missed medication
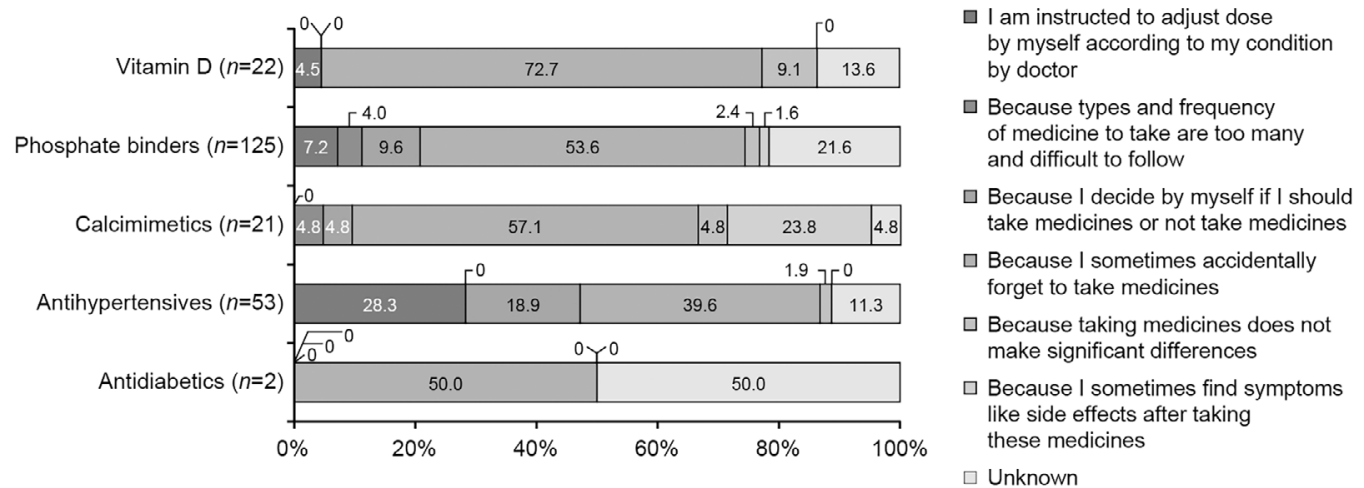

Figure 4. (A) Medication adherence and (B) rationale by class of medication.

remaining reasons for not reporting were "I would have reported leftover medications if asked, but I have never been asked" [59.5\% (47/79)] and "I forget that I have leftover medications when I go to the hospital" [7.6\% (6/79)]. No significant differences in these responses were found across age and gender. However, the percentage of patients who answered, "I would have reported leftover medications if asked, but I have never been asked" was $74.5 \%$ (35/47) for men and $21.3 \%(10 / 47)$ for women, with $19.2 \%(9 / 47)$ in their 50s, 38.3\% (18/47) in their 60s, and $38.3 \%(18 / 47)$ in their 70s. Similarly, the percentage of patients who answered, "they will find out that I am not compliant and it is hard to talk about it" was $81.3 \%$ (13/16) for men and $18.8 \%$ (3/16) for women, with $25.0 \%$ (4/16) in their 50s, 37.5\% (6/ $16)$ in their $60 \mathrm{~s}$, and $37.5 \%(6 / 16)$ in their $70 \mathrm{~s}$.

\section{Compliance by type of medication}

Adherence was high for all types of medications: between $76.7 \%$ for phosphate binders and $95.7 \%$ for antidiabetic medications (Fig. 4).

The most common reason for nonadherence was forgetting to take medications. Vitamin D products were reported as a forgotten medication by $72.7 \%(16 / 22)$ of patients; phosphate binders, $53.6 \%$ (67/125); calcimimetics, $57.1 \%$ (12/21); antihypertensives, 39.6\% (21/53); and antidiabetic medications, $50.0 \%$ (1/2). Other reasons for nonadherence included difficulty managing the high number or frequency of medications [reported for phosphate binders by $4.0 \%$ (5/
125) and for calcimimetics by $4.8 \%(1 / 21)$ ] and undesirable side effects [reported for calcimimetics by $23.8 \%(5 / 21)$; phosphate binders, $1.6 \%$ (2/125); and antihypertensives/antidiabetics, $0 \%$ ].

\section{Perception of medication burden}

Overall, 21.0\% (110/524) of patients reported feeling a mental burden from their oral medication regimen. The reported reasons for mental burden were "too many tablets and types of tablets" in $29.1 \%(32 / 110)$ of patients, "I am worried about side effects" in $17.3 \%$ (19/110), and "taking medications is stressful" in $6.4 \%$ (7/110). In contrast, $65.8 \%$ $(345 / 524)$ of patients answered either "I feel less burden" or "I don't feel any mental burden at all" (Fig. 5). The rationales of patients who claimed no mental burden were "I am accustomed to taking medications" in $11.0 \%$ (38/345) of patients, "I think taking medications is good for my health" in $10.1 \%(35 / 345)$, and "I know taking medications is necessary" in $6.4 \%(22 / 345)$.

\section{A comparison of the perception of medication bur- den with patient preferences}

Among patients reporting mental burden, 86.4\% (95/110) responded that they take medications as instructed by the doctor compared with $93.6 \%$ (323/345) of patients who reported no mental burden. In the questionnaire, patients were asked whether eliminating 1 medication (one tablet) would reduce their mental burden. The response of $37.8 \%$ (198/ 
A. Question: Do you feel a mental burden from taking oral medications?

Feel pill burden: "I feel a significant mental burden" + "I feel mental burden" Not feel pill burden: "I feel less burden" + "I don't feel a mental burden at all"

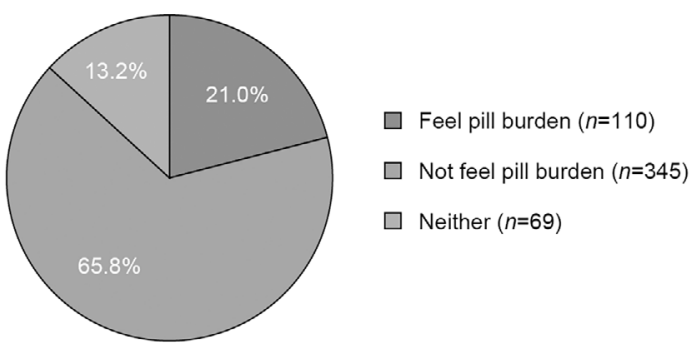

B. Question: Do you think that eliminating 1 medication (1 tablet) will help you?

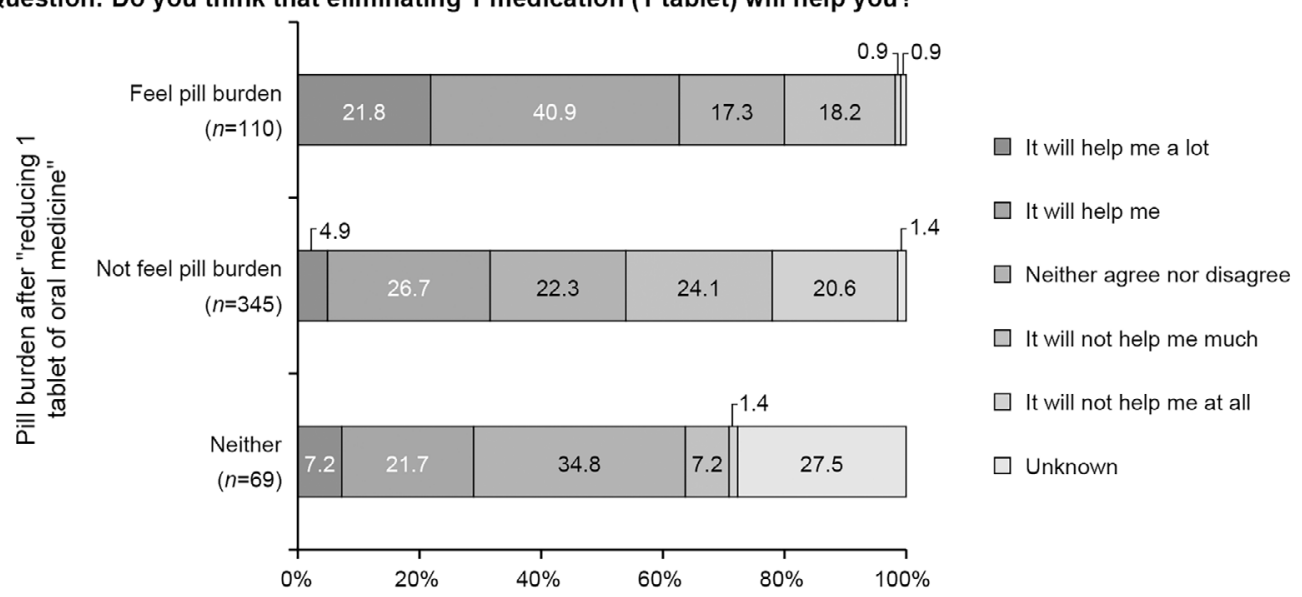

C. Question: Would you rather receive medication injections during dialysis or take oral medications?

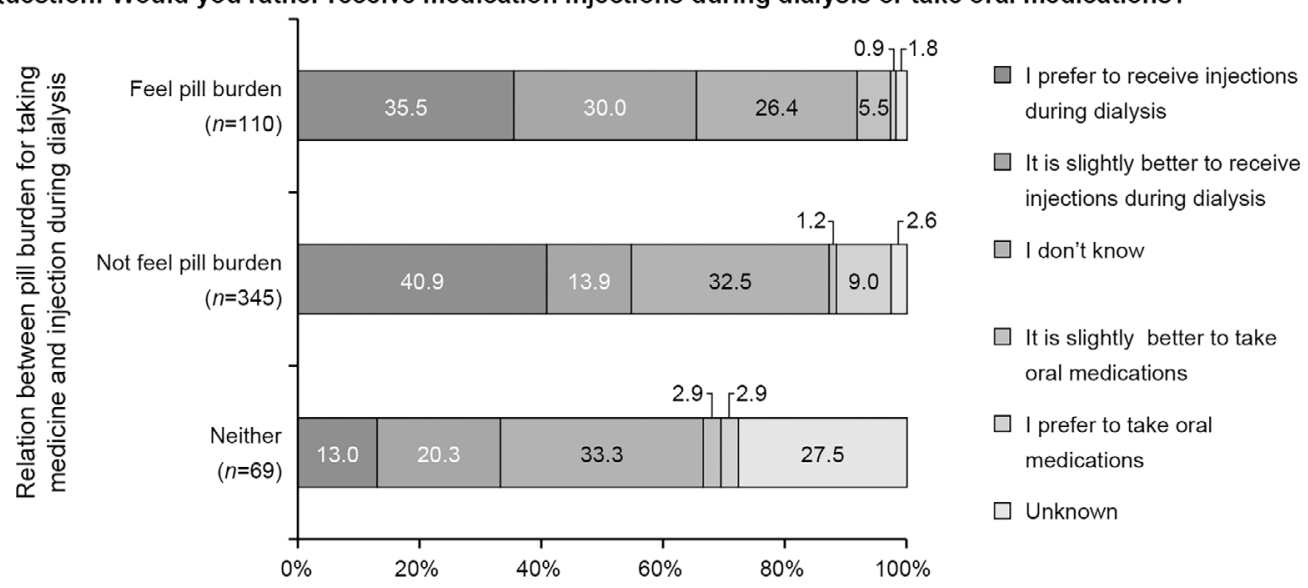

Figure 5. (A) Medication burden, (B) relief of burden by elimination of one medication, and (C) patient preference for injection versus oral medication.

524) of patients was "it will help me a lot" or "it will help me"; of these, $34.8 \%(69 / 198)$ reported mental burden, while $55.1 \%(109 / 198)$ reported no mental burden. The main reasons were "I feel most comfortable taking as few medications as possible," "this can reduce medical expenses," and "this will reduce the risk of side effects." Even among the patients who reported "neither" and "I do not feel a mental burden," 29.0\% (20/69) and 31.6\% (109/345), respectively, reported "it will help me a lot" or "it will help me" to eliminate one medication. Overall, reducing one medication is likely to benefit patients by reducing mental burden.

Similarly, of the $34.5 \%(181 / 524)$ of patients who an- swered, "it will not help me much" and "it will not help me at all" to eliminate 1 medication, $19.1 \%$ (21/110) also reported mental burden, while $44.6 \%$ (154/345) reported no mental burden. The primary reasons reported by these patients included "reducing one medication does not change anything," "medications that are needed shouldn't be eliminated," and "I do not feel any particular burden."

Among the patients who reported a mental burden, $65.5 \%$ (72/110) responded that "I prefer to receive an injection during dialysis" or "it is slightly better to receive an injection during dialysis." Among those who did not report a mental burden or those who responded with "neither," 54.8\% (189/ $345)$ and $33.3 \%$ (23/69) responded with "I prefer to receive 
an injection during dialysis" or "it is slightly better to receive an injection during dialysis," respectively. Patient preference for oral medication was as low as $0.9 \%(1 / 110), 9 \%$ $(31 / 345)$, and $2.9 \%(2 / 69)$ for patients who felt mental burden, felt no mental burden, and neither, respectively (Fig. 5). Primary reasons for preferring oral medications included "I am aware that I am receiving treatment," "I can choose for myself," and "I can stop if I do not like it." The primary reasons for preferring injectables included "injection is more convenient" and "injection prevents me from missing a dose of oral medication."

\section{Discussion}

The results of this survey in maintenance hemodialysis patients showed that medication compliance/adherence was high overall (93.2\%) and higher than the range reported in a recent systematic literature review of 22 trials including 19,322 dialysis patients; the adherence reported from 5 trials only was $81 \%$ (range $65-92 \%$ ) (18).

The majority of patients (approximately 75\%) had been on hemodialysis for $\geq 10$ years, suggesting that the quality of dialysis support in Japan leading to a longer lifespan may be attributed to better adherence. Renal transplantation rates are low in Japan, and the prognosis of patients on hemodialysis is better than in many other countries (19). Furthermore, high-quality medication counseling available in Japan contributes to the ability of patients to understand the importance of treatments and compliance, which may translate directly into higher rates of medication adherence. This supports the importance of thoroughly informing patients about their treatment and involving them in the decision-making process concerning the treatment and management of CKD (20).

In the previous study, of the five different types of oral medications, patients received a greater number of phosphate binders (7.0 tablets daily) and antihypertensive medications (2.8 tablets) than any other medications (2). As shown in Fig. 3, the percentage of leftover phosphate binders was the highest for any medication, suggesting that the number of tablets for a therapy is related to its adherence. However, the high daily medication burden (16 medications) (2) and high adherence $(93.2 \%)$ in these Japanese patients stands in contrast to the lower daily pill burden (9.7 medications) and lower adherence rate (48\%) among 1,238 hemodialysis patients who participated in a study from 54 centers in Italy (13). Therefore, it is possible that high-quality medication counseling concerning the purpose of medications and importance of treatments and compliance can lead to a high degree of adherence among patients.

The most common reason for nonadherence was forgetting a dose, a finding shared by the Italian survey (12). The patients in this study primarily forgot doses of medications prescribed for CKD-MBD, which is of significance because disorders of mineral metabolism are independently associated with cardiovascular and fracture-related morbidity and mortality (21). Only $2.7 \%$ of the respondents who missed medications attributed their nonadherence to the difficulty of managing multiple types and high dosing frequencies of medications.

A majority of patients $(65.8 \%)$ did not feel that their treatment was mentally burdensome, whereas $21.0 \%$ did feel some burden. This may be attributed to the longer dialysis vintage in the unburdened patients, making them more accustomed to their multimodal treatment. However, $62.7 \%$ of patients who felt a mental burden and $31.6 \%$ of patients who did not feel a mental burden indicated that eliminating 1 medication from their regimen would reduce their mental burden. The number of prescribed medications in a given treatment regimen is associated with treatment adherence; therefore, reducing medication burden might improve adherence. However, when modifying the complexity of a treatment regimen, patients' negative attitudes toward medications should also be addressed (13). Interestingly, similar proportions of patients who did $(65.5 \%)$ and did not feel a mental burden (54.8\%) preferred injection during dialysis over oral medication. This preference for injection among patients who did not feel a mental burden indicates that, if given a choice, these patients would choose the convenience of injection, possibly because oral medication requires diet and fluid regulation when on dialysis.

CKD-MBD is a systemic disorder in this patient group that requires treatment for associated parathyroid hormone, calcium, phosphorus, and vitamin D metabolism disorders (4). As a reflection of high treatment adherence, the rate of leftover medication was low at $7.8 \%$ overall and 3.8$8.6 \%$ for CKD-MBD-related drugs (Fig. 3). However, since the dialysis vintage in the majority of patients was $\geq 10$ years (associated with a high treatment adherence), these findings may not reflect the real-world scenario of hemodialysis patients in Japan. The majority of patients (73.2\%) did report leftover medications to healthcare professionals (Fig. 1B). The most common reasons for not reporting leftover medications were either that patients were comfortable with having leftover medications $(24.1 \%)$ or that they found it hard to talk about it, fearing risk of exposure of noncompliance $(20.3 \%)$.

While adherence to medications prescribed for CKDMBD was high overall, the percentage of leftover medications was highest for phosphate binders, possibly because of the multitude of available phosphate binders and their high frequency of administration. Although not directly comparable, the international Dialysis Outcomes and Practice Patterns Study, which included data from 5,262 hemodialysis patients from 12 countries, showed that the proportion of patients who reported nonadherence to phosphate binders at least once in the past month was $45 \%$ overall, ranging from $33 \%$ in Belgium to $57 \%$ in the United States (22). Furthermore, patient preferences that impact adherence to phosphate binders are known to vary with dosage form, taste, number of tablets, and gastric intolerance (8). Therefore, nonadherence to phosphate binders cannot simply be attrib- 
uted to a medication-specific knowledge deficit (23); strategies that engage patients' beliefs regarding their personal need for phosphate binders may improve adherence $(7,24)$.

Patients specifically pointed out that calcimimetics cause side effects that impact their treatment adherence. Clinical trials have also shown that calcimimetics cause side effects that limit their tolerance (25). Among a large retrospective cohort dataset of dialysis patients in the United States, the percentage of patients who were adherent to their medications ( $\geq 80 \%$ medication possession ratio) was $22 \%$ for phosphate binders and $35 \%$ for cinacalcet (26). Broadly, these findings suggest that physicians should modify their treatment goals to maximize the patients' quality of life by understanding the domains that are of most concern to each patient (27).

Overall, on comparing the findings of 2 previous reports in the literature (a systematic literature review that included studies from 1971 to 2008 and a report from a single hospital in Riyadh, Saudi Arabia), the rate of nonadherence to oral medication ranged from $3 \%$ to $80 \%(3,28)$. More than half of the included studies in the literature review reported nonadherence rates of $\geq 50 \%$ (mean $67 \%$ ) (3). However, we observed an extremely low rate $(<10 \%)$ of nonadherence to oral medication in Japan despite the highest number of tablets consumed daily being phosphate binders (2). This may be further influenced by the unique attributes in Japan: differences in insurance schemes $(100 \%$ coverage), differences in availability of choice of drugs, and Japanese patients having the longest dialysis vintage in the world.

Study limitations include the fact that the survey was patient-reported, and individual bias regarding variations in responses from different regions in Japan could not be ruled out. In addition, the questionnaire items regarding leftover medications were not conducted in or verified by a pharmacy. Furthermore, translation of the questionnaire from Japanese to English may not adequately represent the perceptions of Japanese patients.

\section{Conclusion}

The results of this survey show that overall medication adherence is high in Japanese patients on maintenance hemodialysis, which is supported by a low rate of leftover medication. The results indicate that while many patients perceive an absence of mental burden, they still prefer to avoid oral medication when possible. However, these results cannot be extrapolated to the entire hemodialysis population in Japan due to the relatively long dialysis vintage of the respondents in this study. In addition, medication counseling was optimal, and the level of patient understanding was high. Treatment adherence and associated rationales varied according to the type of medications the patients were taking.

Author's disclosure of potential Conflicts of Interest (COI).

Takashi Shigematsu: Honoraria, Chugai Pharmaceutical and
Kyowa Hakko Kirin.

\section{Financial Support}

This survey was provided, collected, and summarized by Social Survey Research Information. This study was funded by Ono Pharmaceutical.

\section{Acknowledgement}

Editorial support in the preparation of this manuscript was provided by Annirudha Chillar, MD, PhD.

\section{References}

1. Tozawa M, Iseki K, Iseki C, et al. Analysis of drug prescription in chronic haemodialysis patients. Nephrol Dial Transplant 17: 18191824, 2002.

2. Iwashita Y, Ohya M, Kunimoto S, et al. A survey of drug burden in patients undergoing maintenance hemodialysis in Japan. Intern Med 57: 2937-2944, 2018.

3. Schmid H, Hartmann B, Schiffl H. Adherence to prescribed oral medication in adult patients undergoing chronic hemodialysis: a critical review of the literature. Eur J Med Res 14: 185-190, 2009.

4. Kidney Disease; Improving Global Outcomes (KDIGO) CKDMBD Update Work Group. KDIGO 2017 Clinical Practice Guideline Update for the Diagnosis, Evaluation, Prevention, and Treatment of Chronic Kidney Disease-Mineral and Bone Disorder (CKD-MBD). Kidney Int Suppl 7: 1-59, 2017.

5. Battistella M, Fleites R, Wong R, Jassal SV. Development, validation, and implementation of a medication adherence survey to seek a better understanding of the hemodialysis patient. Clin Nephrol 85: 12-22, 2006.

6. Chiu YW, Teitelbaum I, Misra M, de Leon EM, Adzize T, Mehrotra R. Pill burden, adherence, hyperphosphatemia, and quality of life in maintenance dialysis patients. Clin J Am Soc Nephrol 4: 1089-1096, 2009.

7. Chater AM, Parham R, Riley S, Hutchison AJ, Horne R. Profiling patient attitudes to phosphate binding medication: a route to personalising treatment and adherence support. Psychol Health 29: 1407-1420, 2014.

8. Arenas MD, Malek T, Álvarez-Ude F, Gil MT, Moledous A, Reig-Ferrer A. Phosphorus binders: preferences of patients on haemodialysis and its impact on treatment compliance and phosphorus control. Nefrologia 30: 522-530, 2010 (in Spanish, Abstract in English).

9. Masakane I, Nakai S, Ogata S, et al. An overview of regular dialysis treatment in Japan (as of 31 December 2013). Ther Apher Dial 19: 540-574, 2015.

10. Jin J, Sklar GE, Sen Oh VM, et al. Factors affecting therapeutic compliance: A review from the patient's perspective. Ther Clin Risk Manag 4: 269-286, 2008.

11. Dolores Arenas M, Pérez-Garcia R, Bennouna M, et al. Improvement of therapeutic compliance in haemodialysis patients with poor phosphorus control and adherence to treatment with binders: COMQUELFOS study. Nefrologia 33: 196-203, 2013 (in Spanish, Abstract in English).

12. Sgnaolin V, Figueiredo AE. Adherence to pharmacological treatment in adult patients undergoing hemodialysis). J Bras Nefrol 34: 109-116, 2012 (in Portuguese, Abstract in English).

13. Neri L, Martini A, Andreucci VE, Gallieni M, Rey LA, Brancaccio D. Regimen complexity and prescription adherence in dialysis patients. Am J Nephrol 34: 71-76, 2011.

14. The Ministry of Health, Labour and Welfare. The 262nd general assembly of the Central Social Insurance Medical Council, Agenda No. 3, Dispensing fee. 2013 Dec. 4. [Internet]. [cited 2018 Oct. 9]. Available from: http://www.mhlw.go.jp/stf/shingi/0000031125.h 
tml (in Japanese).

15. Shuzo Nishimura HCRII (2015 August 18) Medical White Paper 2015 - 2016 Edition. Japan Medical Planning [Internet]. [cited 2018 Oct 9]. Available from: http://www.jmp.co.jp/jmp_wp/

16. Nakamura T, Kishimoto K, Yamaura K, Fukushima N. A qualitative study: Factors related to the prevalence of leftover drugs for senior patients in Japan. Jpn J Soc Pharm 35: 2-9, 2016 (in Japanese).

17. The Ministry of Health, Labour and Welfare. The 311th general assembly of the Central Social Insurance Medical Council, Agenda No. 3, Optimization of drug use. 2015 Nov 6. [Internet]. [cited 2018 Oct 9]. Available from: http://www.mhlw.go.jp/stf/shingi2/00 00102937.html (in Japanese).

18. Murali KM, Mullan J, Chen JH, Roodenrys S, Lonergan M. Medication adherence in randomized controlled trials evaluating cardiovascular or mortality outcomes in dialysis patients: a systematic review. BMC Nephrol 18: 42, 2017.

19. Foote C, Kotwal S, Gallagher M, Cass A, Brown M, Jardine M. Survival outcomes of supportive care versus dialysis therapies for elderly patients with end-stage kidney disease: a systematic review and meta-analysis. Nephrology (Carlton) 21: 241-253, 2016.

20. Keeney S, McKenna H. An exploration of the choices of patients with chronic kidney disease. Patient Prefer Adherence 8: 14651474, 2014.

21. Block GA, Klassen PS, Lazarus JM, Ofsthun N, Lowrie EG, Chertow GM. Mineral metabolism, mortality, and morbidity in maintenance hemodialysis. J Am Soc Nephrol 15: 2208-2218,
2004.

22. Fissell RB, Karaboyas A, Bieber BA, et al. Phosphate binder pill burden, patient-reported non-adherence, and mineral bone disorder markers: findings from the DOPPS. Hemodial Int 20: 38-49, 2016.

23. Joson CG, Henry SL, Kim S, et al. Patient-reported factors associated with poor phosphorus control in a maintenance hemodialysis population. J Ren Nutr 26: 141-148, 2016.

24. Van Camp YP, Vrijens B, Abraham I, Van Rompaey B, Elseviers MM. Adherence to phosphate binders in hemodialysis patients: prevalence and determinants. J Nephrol 27: 673-679, 2014.

25. Bover J, Ureña P, Ruiz-Garcia $C$, et al. Clinical and practical use of calcimimetics in dialysis patients with secondary hyperparathyroidism. Clin J Am Soc Nephrol 11: 161-174, 2016.

26. Park H, Rascati KL, Lawson KA, Barner JC, Richards KM, Malone DC. Adherence and persistence to prescribed medication therapy among Medicare part $\mathrm{D}$ beneficiaries on dialysis: comparisons of benefit type and benefit phase. J Manag Care Spec Pharm 20: 862-876, 2014

27. Finkelstein FO. Performance measures in dialysis facilities: what is the goal? Clin J Am Soc Nephrol 10: 156-158, 2015.

28. Alkatheri AM, Alyousif SM, Alshabanah N, et al. Medication adherence among adult patients on hemodialysis. Saudi J Kidney Dis Transpl 25: 762-768, 2014.

The Internal Medicine is an Open Access journal distributed under the Creative Commons Attribution-NonCommercial-NoDerivatives 4.0 International License. To view the details of this license, please visit (https://creativecommons.org/licenses/ by-nc-nd/4.0/).

(C) 2019 The Japanese Society of Internal Medicine Intern Med 58: 2595-2603, 2019 